\title{
The impact of the Goesan dam on fish communities up- and downstream
}

\author{
Mi-Young Song ${ }^{1}$, Wan-Ok Lee ${ }^{1}$, Kyung-Hwan Kim ${ }^{1}$, Young-Seuk Park ${ }^{2 *}$ and Mi-Jung Bae ${ }^{3 *}$ \\ 1 Inland Fisheries Research Institute, National Institute of Fisheries Science, Gyeonggi-do 12453, Republic of Korea \\ 2 Department of Life and Nanopharmaceutical Sciences, and Department of Biology, Kyung Hee University, Seoul 130-701, \\ Republic of Korea \\ 3 Freshwater Biodiversity Research Division, Nakdonggang National Institute of Biological Resources, Sangju, Gyeongsangbuk-do, \\ 37242, Republic of Korea
}

Received 3 July 2015; Accepted 18 December 2015

\begin{abstract}
Dams can cause fragmentation of the natural structure and function of fish communities up- and downstream of the dam. In this study, we examined the effects of the Goesan Dam on the longitudinal distribution of fish in the Dal stream, using two computational methods: a self-organizing map (SOM) and spatial autocorrelation. Fish were collected at 16 different study sites in two seasons (spring and autumn). SOM classified the study sites into four clusters (1-4), reflecting differences in the longitudinal distribution patterns of fish, and the effects of the dam on fish community composition. Samples in clusters 1 and 2 mostly originated from tributaries and the upstream section of the dam, whereas samples in cluster 4 originated from downstream study sites of the dam. Cluster 3 included study sites originating directly from up- and downstream of the dam. Species turnover and spatial autocorrelation results confirmed the fish community alteration near the dam. Species turnover was the highest between study sites directly up- and downstream of the dam. The Mantel correlogram was positive when applied to short distances between the study sites. However, it was negative for the farthest distance, including sites near the dam, indicating that the dam caused significant alterations to the fish community. Overall, our results suggest that the habitat alterations (e.g., fragmentation of longitudinal gradients and disruption of flow regimes) due to dam construction have caused fragmentation of fish communities.
\end{abstract}

Key words: Fish community / indicator species / spatial autocorrelation / fragmentation / dams / selforganizing map

\section{Introduction}

Streams have been continuously disrupted by various anthropogenic disturbances, including the introduction of invasive species, dam constructions, impoundments, water diversions, land use change, river channelization, water abstraction and effluents from wastewater treatment plants (Bae et al., 2015). Among them, dams are one of the most severe anthropogenic disturbances that result in stream ecosystem alterations (Poff and Hart, 2002; March et al., 2003). In natural flow regimes, the intensity, frequency and magnitude of natural disturbances, including extreme peak and low flows, can vary annually, seasonally and daily, despite their predictability (Gasith and Resh, 1999; Power et al., 2008). Therefore, many

\footnotetext{
*Corresponding authors: parkys@khu.ac.kr, mjbae@nnibr. re.kr
}

native freshwater fish have evolved life-history strategies to cope with natural hydrological variability, as well as rapid recovery rates from natural disturbances (Bonada et al., 2007; Power et al., 2008; Yarnell et al., 2010). Dams are, however, the primary reason for altered flow regimes, including changes from lotic to lentic habitats, reduced seasonality of water flow (or variability; Poff et al., 2007), and increases in short-term minimum flows and decreases in short-term maximum flows (Magilligan and Nislow, 2005). Furthermore, dams fragment river continuity, and change the downstream thermal regime (Cushman, 1985; Bain et al., 1988; Kinsolving and Bain, 1993; Travnicheck et al., 1995; Schmidt et al., 1998).

Under natural conditions, a fish community changes longitudinally from mainly small-sized, insectivorous and herbivorous fish upstream, to large-sized, omnivorous and piscivorous fish downstream (Matthews, 1998). Fish are more abundant in larger rivers (i.e., higher species 
richness, density and biomass), where the habitat diversity is higher and stream sizes are larger (Ostrand and Wilde, 2002; Vila-Gispert et al., 2002; Araújo et al., 2009). However, native species that are specialized to their original habitat (e.g., natural flow variability) have difficulties surviving in anthropogenic disturbed habitats (e.g., changes from lotic into lentic habitat conditions following dam construction) (Mims and Olden, 2012, 2013). For example, since dams homogenize and disconnect the habitats, competition between resident fish and introduced fish for spawning or food resources can increase (Helms et al., 2011). Additionally, invasive species that lack the biological and behavioral mechanisms to cope with the original and natural flow regimes (Kiernan et al., 2012) have a higher chance of successfully colonizing and becoming established in the altered habitats (Falke and Gido, 2006; Johnson et al., 2008). Thus, in many regulated streams and rivers, native fish that have adapted to their natural flow regimes have great difficulties competing with invasive fish. As a consequence, they are replaced by invasive fish species that adapt more easily to new habitat conditions (e.g., constant flows and lower habitat complexity) (Moyle, 2002; Moyle and Marchetti, 2006). Furthermore, shifts in flow regimes can cause homogenized communities composed primarily of alien species, such as common carp, which easily establish in altered habitats (Kiernan et al., 2012). In sum, understanding and recognizing the impacts of dam constructions (e.g., spatial disruptions and alterations of flow regimes) on fish communities should be a priority for managing aquatic resources effectively. In this study, we characterized the alteration of fish communities caused by a dam in a temperate stream by: (1) investigating distribution patterns of the stream's fish communities, using the computational technique of a self-organizing map (SOM), and (2) quantifying spatial patterns of the fish communities, using spatial autocorrelations along the up-downstream gradient.

\section{Materials and methods}

\section{Ecological data}

We collected samples at 16 study sites on the Dal stream (total length: $123 \mathrm{~km}$, catchment area: $1614.4 \mathrm{~km}^{2}$ ), which is a tributary of the Han River in Korea (Fig. 1): Ten study sites (M1-M10) were situated in the main channel and others (T1-T6) were in its tributaries. The Goesan Dam is located between sites M7 and M8, and its reservoir is situated in the inland fisheries resources protection area. The Geosan Dam was built in 1957, and it was the first hydroelectric dam in Korea. Its maximum depth is $21.9 \mathrm{~m}$, and the dam measures $28 \mathrm{~m}$ in height, $41 \mathrm{~m}$ in width and $171 \mathrm{~m}$ in length. The dam's total reservoir capacity contains $1.5 \times 10^{7} \mathrm{~m}^{3}$, and its accompanying watershed measures $671 \mathrm{~km}^{2}$.

The fish were sampled from various habitats at each study site, using a standardized protocol based on the catch per unit effort (MOE/NIER, 2008). Casting nets (mesh size: $14 \mathrm{~mm}$, net size: $4.5 \mathrm{~m}^{2}=\pi \times 1.22 \mathrm{~m}$, ten times) and kick nets (mesh size: $12 \mathrm{~mm}$, net size: $1.35 \mathrm{~m}^{2}=$ $1.5 \times 0.9 \mathrm{~m}, 30 \mathrm{~min}$, two persons) were used to sample shallow areas (all study sites). At M7 and M10, fyke nets (mesh size: $24 \mathrm{~mm}$, net size: leader net $10 \mathrm{~m}$, bag net $6.5 \mathrm{~m}$ ) were additionally employed with casting nets and kick nets (riparian areas at these sites) because the mid parts of the sites were too deep ( $>2 \mathrm{~m}$ in water depth) to use casting and kick nets for collecting fish. In the shallow areas, a stream segment of $100 \mathrm{~m}$ at each site was sampled for $30 \mathrm{~min}$. In the deep areas, the fyke net was installed and collected after 2 days. All collected fishes were identified to species level based on Kim and Park (2002), and their weights as biomass were measured to the nearest $0.1 \mathrm{~g}$ in the field. Fish were sampled in the spring (June) and autumn (October) of 2010.

All species were assigned to one of four trophic guilds (i.e., herbivores, insectivores, omnivores or piscivores) according to the guidelines of the "National Surveys for Stream Ecosystem Health" in Korea (MOE/NEIR, 2008) and the "Freshwater Fish of Korea" (Kim and Park, 2002).

Physico-chemical factors such as dissolved oxygen concentration (DO, mg. $\mathrm{L}^{-1}$ ), $\mathrm{pH}$, and electric conductivity (conductivity, $\mu \mathrm{S} . \mathrm{cm}^{-1}$ ) were additionally measured at the sites, using a multifunction meter (YSI, 556MPS, YSI Inc., USA). Hydrological factors such as stream width $(\mathrm{m})$, water width $(\mathrm{m})$, depth $(\mathrm{cm})$ and current velocity (m.s ${ }^{-1}$, Flowatch, JDC) were recorded at each study site. These hydrological factors were measured every $10 \mathrm{~m}$ within our study sites. The proportion of land cover (i.e., urban area, paddy field and forest) was analyzed for each transect within each riparian zone, with $200 \mathrm{~m}$ wide buffers and at $1 \mathrm{~km}$ distance from the study sites, using a digital map in ArcGIS (version 9.3) (see Bae et al., 2014 for details). Altitude (m), slope (\%) and distance from source (DFS, $\mathrm{km}$ ) were also extracted from a digital map using ArcGIS (version 9.3).

\section{Data analysis}

A SOM (Kohonen, 2001) was used to characterize the distribution pattern of fish communities at different study sites. A SOM consists of an input and an output layer. The input layer receives its values from the initial data matrix (40 species and 32 samples), whereas the output layer consists of output units in a hexagonal lattice (neurons), usually arranged into a two-dimensional grid to provide better visualization. The number of output units was determined as $5 \times \sqrt{\text { number of samples }}$ based on Vesanto (2000) and Céréghino and Park (2009). We chose 20 $(N=4 \times 5)$ output units.

After the learning process of the SOM, the SOM units were classified based on a hierarchical cluster analysis using Ward's linkage method with the Euclidean distance measure (Legendre and Legendre, 1998; Céréghino and Park, 2009). Prior to the SOM application, species 


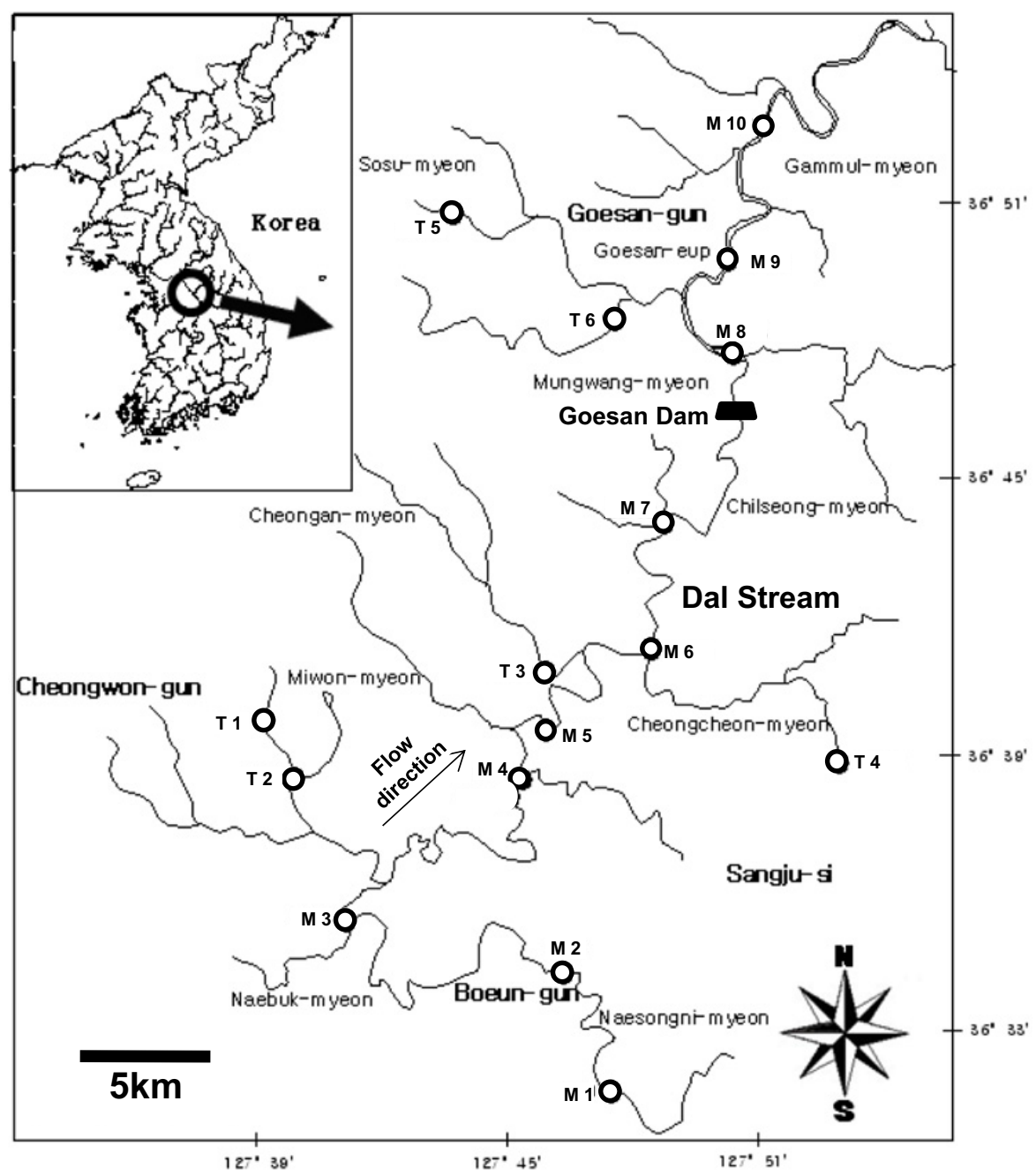

Fig. 1. Study sites in the Dal Stream, Korea.

abundance data were transformed with a natural logarithm $(\log (x+1))$. The transformed values were subsequently rescaled to minimum (0) and maximum (1) values, before training the model. We used the functions in the SOM toolbox (Alhoniemi et al., 2000) for training the SOM in Matlab version 6.1 (The Mathworks, 2001). As input data for our study, we used both spring and autumn data (number of input data: 32 sites, consisting of 16 study sites sampled both seasons).

A Multi-Response Permutation Procedure was applied to test for significant differences among the clusters from the SOM analysis, using PC-ORD version 5.0 (McCune and Mefford, 2006). To evaluate the indicator species in each SOM cluster, we applied an indicator species analysis (IndVal, Dufrêne and Legendre, 1997). Indicator species were selected by an indicator value, which is calculated as the product of its relative abundance and its relative frequency and ranges from 0 (no indication) to 100 (perfect indication) (Peterson and Keister, 2003). Species with an IndVal $>25$ were considered indicator species (e.g., individuals of a species are present in more than $50 \%$ of the samples in one cluster, and the relative abundance of the indicator species in the clusters is more than $50 \%$ ) (Dufrêne and Legendre, 1997; Chaves et al., 2008). The significance of the indicator values for each species was tested with a Monte Carlo permutation (9999 random permutations), using the PC-ORD version 5.0 (McCune and Mefford, 2006).

A Kruskal-Wallis (K-W) test was used to compare the differences in environmental variables and community indices among clusters defined by the SOM. Nonparametric Dunn's multiple comparison tests were used for post-hoc comparisons. Both the $\mathrm{K}-\mathrm{W}$ test and Dunn's multiple comparison tests were conducted using Statistica version 8.0 (Statsoft, Inc., 2007).

To determine the effects of the dam on the distribution patterns of fish, we applied two analytical methods: species turnover (Albert and Reis, 2011), and a spatial autocorrelation based on the Mantel test (Mantel, 1967; Sokal and Rohlf, 1995; Legendre and Legendre, 1998). Species turnover per site was computed as:

$$
\text { Turnover }=\frac{\mathrm{SR} 1-C}{\mathrm{SR} 2-C}
$$




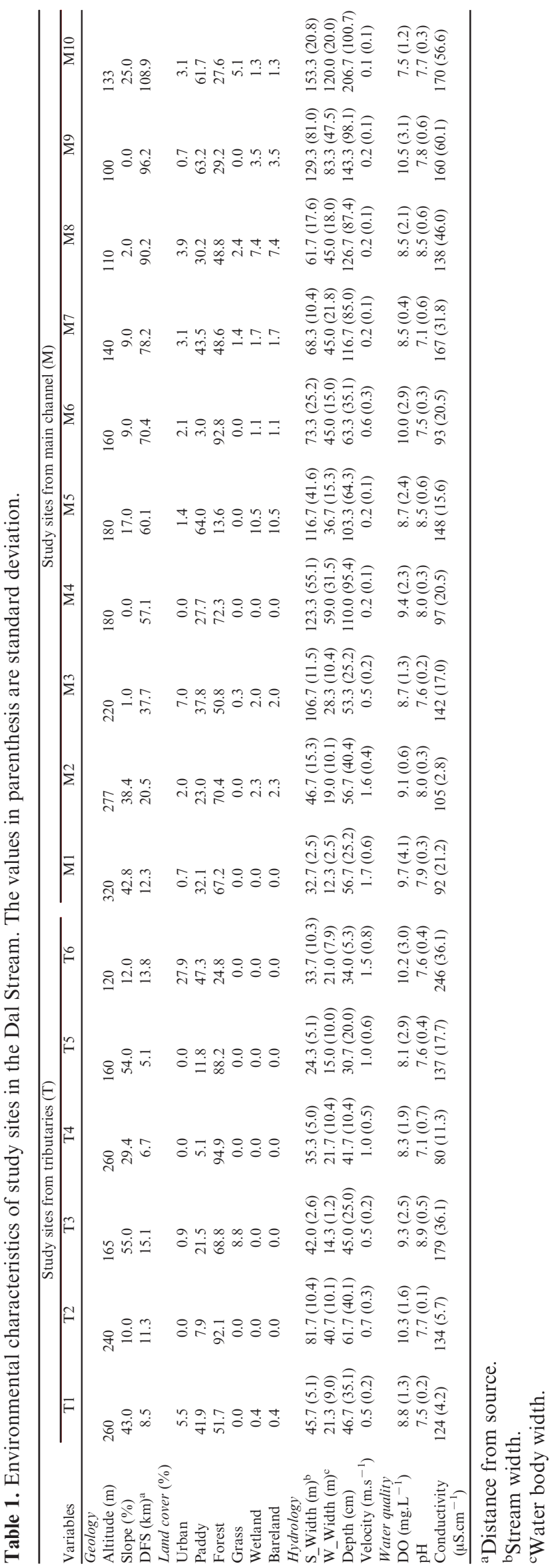

where SR1 is the total number of species in the upstream site, SR2 is the total number of species in the downstream site, and $C$ is the overlapping number of species between the two adjacent study sites. We computed species turnover between the two nearest sites, and higher turnover values indicate large differences in species composition between the two nearby study sites. Before calculating the spatial autocorrelation, geographical distance based on DFS and stream fish dissimilarities were calculated.

To interpret the dissimilarity of fish communities caused by the dam, the Bray-Curtis distance was applied. Abundance values were transformed with a natural logarithm $(\log (x+1))$ prior to the analysis, in order to reduce the variation in abundances. To compute the spatial autocorrelation, and hence interpret the longitudinal disruption of the fish community, we used the study sites within the main tributary, as it has the longest stream length (M1-M10). In addition, the significance of the Mantel test statistic $\left(r_{\mathrm{M}}\right)$ was evaluated based on Monte Carlo permutations (1000 random permutations). Subsequently, the Mantel correlogram (Oden and Sokal, 1986) was applied to determine the spatial structure of the fish communities. The geographical distance matrix was divided into seven classes based on the Sturge's rule (Legendre and Legendre, 1998). A spatial autocorrelation was conducted with the vegan package (Oksanen et al., 2007) using R software (http://cran.r-project.org). Species turnover and spatial autocorrelation were computed separately for spring and autumn, as well as averages for both seasons combined.

\section{Results}

\section{Environmental characteristics}

The water quality of all study sites was similar, reflecting undisturbed or slightly disturbed conditions (DO: $8.0-11.9$ mg. $\mathrm{L}^{-1}$, pH: $7.1-8.9$ and conductivity: 80-246 $\mu \mathrm{S} . \mathrm{cm}^{-1}$, Table 1). Current velocity decreased from upstream to downstream from 1.7 to $0.1 \mathrm{~m} . \mathrm{s}^{-1}$ (M1-M10, respectively). At most study sites, the proportion of forest area was the highest, although for four sites (T6, M5, M9 and M10) paddy fields covered the largest proportion of area (Table 1).

\section{Fish community}

In total, 40 species ( 1 class, 4 orders and 11 families) with 2785 individuals were identified (Appendix 1). Species belonging to the Cyprinidae family were dominant in both abundance and biomass (representing $83.3 \%$ of the total catch by numbers and $52.3 \%$ of biomass). Zacco platypus (33.2\% of total abundance) and Zacco koreanus $(10.7 \%)$ were the most abundant species in numbers, whereas Micropterus salmoides (39.4\% of total biomass), 
(a) 口 Spring $\square$ Autumn

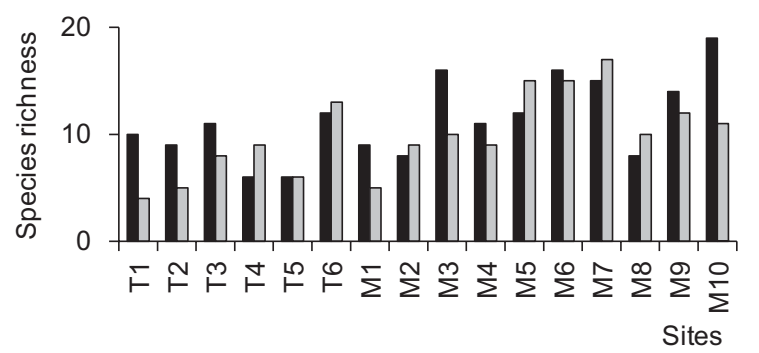

(c) $\square$ herbivores $\square$ insectivores $\square$ omnivores $\square$ piscivores

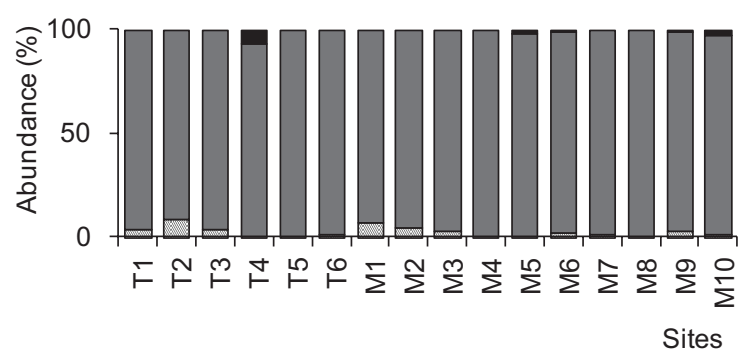

(e) $\square$ herbivores $\square$ insectivores $\square$ omnivores $\square$ piscivores

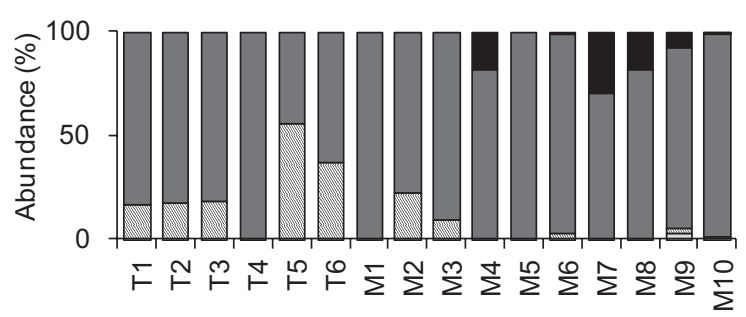

Sites (b)

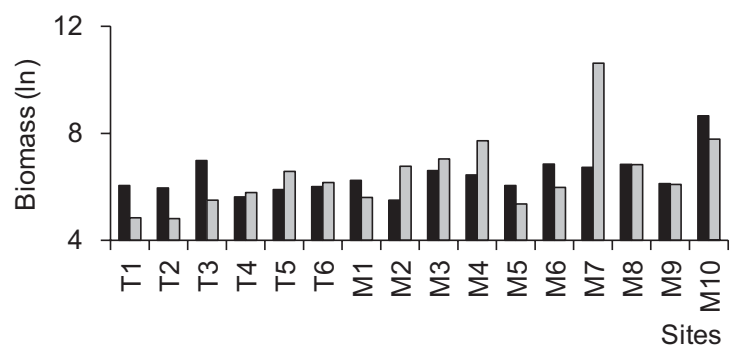

(d) $\square$ herbivores $\square$ insectivores $\square$ omnivores $\square$ piscivores

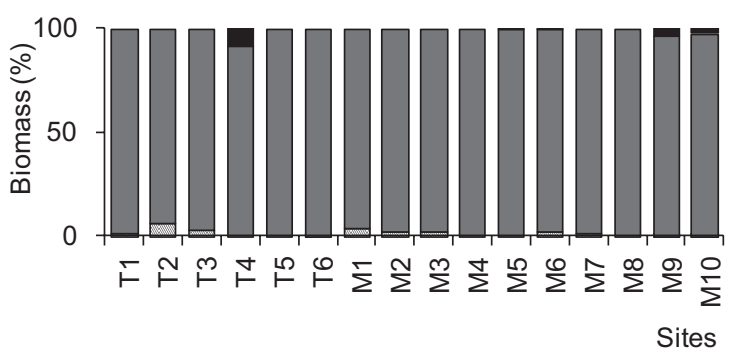

(f) $\square$ herbivores $\square$ insectivores $\square$ omnivores $\square$ piscivores

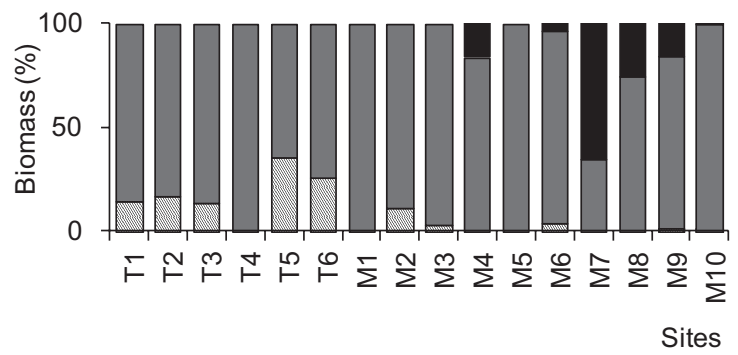

Fig. 2. The changes of species richness (a), biomass (b) and the relative ratios of trophic guilds based on the abundance and biomass in spring (c, d) and in autumn (e, f).

Hemibarbus labeo $(13.6 \%)$ and Z. platypus (10.9\%) represented large portions of the total biomass. Among the 40 species in total, 17 species were endemic to Korea (e.g., Rhodeus uyekii and Acheilognathus signifier). One exotic species, M. salmoides, was collected at two study sites (M4 and M7). Overall, species richness increased from upstream to downstream just before the dam location (i.e., spring: from 6 (T5) to 16 (M6) and autumn from 4 (T1) to 17 (M7)) (Fig. 2). In contrast, species richness decreased abruptly downstream of the dam (M8, spring: 10 and autumn: 8). For trophic guilds, omnivores showed the highest proportion of abundance and biomass at all study sites (72.2-99.2\% in abundance and $66.8-99.8 \%$ in biomass). In addition, insectivore abundance was higher in the upper streams and tributaries than downstream, whereas the proportion of piscivores was highest directly upstream before the dam (M7, abundance: $14.9 \%$ and biomass: $32.8 \%$ for spring and autumn combined, and M7 in autumn: 29.8 and $65.8 \%$, respectively), and gradually decreased downstream of the dam.

\section{Classification of study sites}

The study sites were characterized according to the longitudinal gradient and the location of the dam based on the similarity of fish communities through the learning process of a SOM (Fig. 3(a) and (b)). The SOM units were classified into four clusters (1-4), based on a hierarchical cluster analysis using the Ward linkage method with the Euclidean distance measure. MRPP showed significant differences among the four clusters $(A=0.09, P<0.01)$. The SOM clusters reflected the effects of the dam, as well as the longitudinal gradient of study sites. For example, the samples from the tributary sites (T1-T6) and the samples before the dam (M1-M6) were grouped in clusters 1 and 2, while the samples downstream of the dam (M8-M10) were assigned to cluster 4.

Altitude and slope were higher in clusters $1(206 \mathrm{~m})$ and $2(211 \mathrm{~m})$ (Dunn's test, $P<0.05)$, as they mainly include the upstream study sites (Table 2). However, DFS (60.5 and $90.3 \mathrm{~km}$ in clusters 3 and 4, respectively), stream width $(95$ and $111 \mathrm{~m})$ and water width $(50$ and $65 \mathrm{~m})$ were higher 
(a)

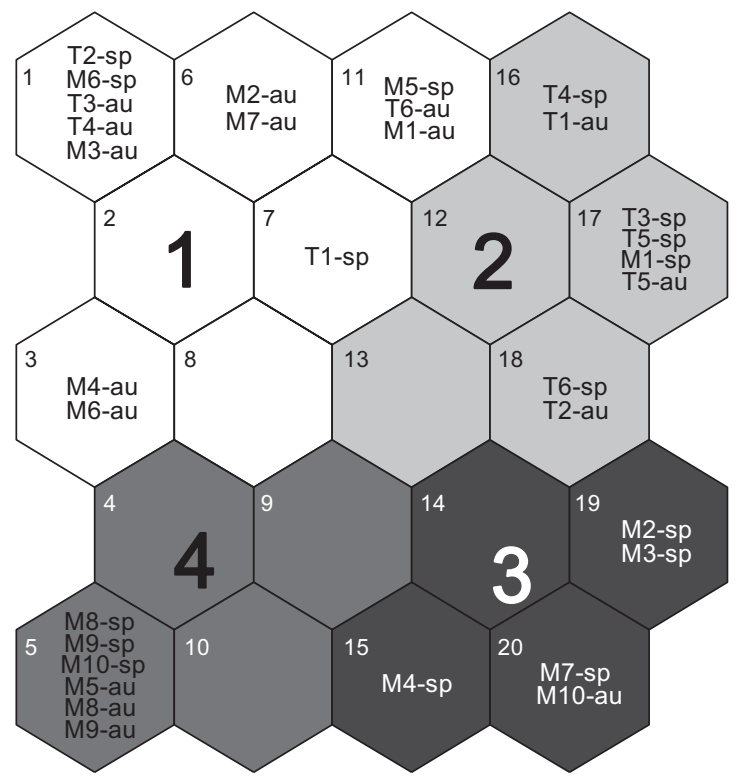

(b)

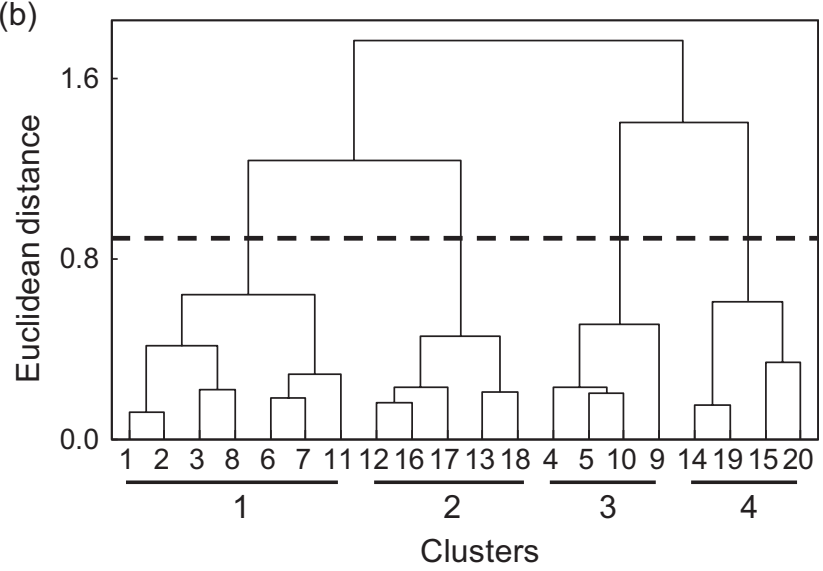

Fig. 3. Classification of samples through the learning process of SOM based on fish abundance in Dal Stream, Korea. (a) Ordination of study site on SOM, (b) Classification of the SOM units based on a hierarchical cluster analysis with the Ward linkage method using Euclidean distance measure. In sample units, first two letters represent site name (e.g., T1, T2, etc.) and last two letters indicate seasons (i.e., sp: spring and au: autumn). Number in each grid of SOM map in Fig. 3(a) and clusters in Fig. 3(b) represent the number (i.e., grid order in downward) of grid in the SOM map.

in clusters 3 and 4, respectively, and current velocity was lower in cluster $3\left(0.5 \mathrm{~m} . \mathrm{s}^{-1}\right)$ and $4\left(0.4 \mathrm{~m} . \mathrm{s}^{-1}\right)$. For land cover types, even though there was no significant difference among the clusters, the proportion of forest was higher in clusters 1 and 2, whereas the proportion of paddy fields was higher in cluster 4 (Table 2).

Considering the differences in trophic guilds based on the relative proportion of abundance and biomass, the proportion of piscivore abundance and biomass was relatively high in clusters 3 (10.2 and $48.4 \%$, respectively) and 4 (4.9 and $24 \%$, respectively). For insectivores, abundance and biomass were highest in cluster 2
(15.2 and $24.1 \%$, respectively), although these were not significantly different from the other clusters.

\section{Indicator species}

Based on the IndVal, 15 indicator fish species were selected in the SOM clusters $(P<0.05)$ (Table 3$)$. For cluster 1, mostly rheophilic species were selected as indicator species, such as Z. koreanus and Liobagrus andersoni, whereas for cluster 3 , lentic species such as Carassius auratus, M. salmoides and Cyprinus carpio were selected. Finally, for cluster 4, lotic and large river preferring species, such as Microphysogobio longidorsalis, Acheilognathus yamatsutae and Coreoleuciscus splendidus were selected.

\section{Longitudinal disruption of fish communities}

The species turnover rate between the sites right before and after the dam was highest overall (4.67 for spring and autumn combined, 1.54 in spring and 2.75 in autumn), although in autumn the rate (3.50) was the highest between site M3 and M4 (Fig. 4(a)). The spatial autocorrelation comparing fish abundance and geographic distances was statistically significant for both seasons combined, and in autumn (combined: $r_{\mathrm{M}}=0.54$ and $P=0.001$; spring: $r_{\mathrm{M}}=0.18$ and $P=0.157$ and autumn: $r_{\mathrm{M}}=0.53$ and $P=0.001$, respectively), based on the Mantel tests (Fig. 4(b)). Overall, the corresponding Mantel correlogram for fish abundance showed a positive autocorrelation for the shortest geographical distance (Mantel coefficients: $0.30, P=0.03$ in average data) and a negative autocorrelation with the farthest geographical distance (Mantel coefficients: $-0.38, P=0.03$ ). In autumn, the pattern of spatial autocorrelation with the shortest distance (Mantel coefficients: $0.22, P=0.04$ ) and with the longest distance (Mantel coefficients $0.44, P=0.02$ ) was similar with the pattern of spring and autumn combined. However, for the distance within $36 \mathrm{~km}$, the Mantel coefficient was positive as well, unlike in spring, representing seasonal-specific effects.

\section{Discussion}

SOM presented the dissimilarity of fish community composition between up- and downstream of the dam, indicating that the fish community in the studied stream has been spatially fragmented by the impacts of the dam. The study sites in the tributaries and upstream of the dam were mainly grouped in clusters $1-2$, whereas the samples from the downstream sites, especially downstream of the dam, were grouped in cluster 4. Species turnover and spatial autocorrelation revealed large differences in fish communities between sites directly before and after the dam. In addition, these analyses indicated a decreased longitudinal connectivity across the study stream due to 
Table 2. Difference (mean (standard error)) in environmental variables and trophic guilds among four clusters defined in SOM. Different letters indicate statistically significant differences among the clusters based on Dunn's multiple comparison tests after a Kruskal-Wallis test $(P<0.05)$.

\begin{tabular}{|c|c|c|c|c|}
\hline \multirow[b]{2}{*}{ Variables } & \multicolumn{4}{|c|}{ Clusters } \\
\hline & 1 & 2 & 3 & 4 \\
\hline \multicolumn{5}{|l|}{$\overline{\text { Geology }}$} \\
\hline Altitude (m) & $206(17)^{\mathrm{a}}$ & $211(24)^{\mathrm{a}}$ & $190(27)^{\mathrm{ab}}$ & $122(13)^{\mathrm{b}}$ \\
\hline Slope $(\%)$ & $21.2(5.1)^{\mathrm{a}}$ & $37.5(6.5)^{\mathrm{a}}$ & $14.7(7.4)^{\mathrm{ab}}$ & $7.7(4.4)^{\mathrm{b}}$ \\
\hline DFS $(\mathrm{km})$ & $35.5(7.6)^{b c}$ & $9.7(1.4)^{\mathrm{c}}$ & $60.5(15.5)^{\mathrm{ab}}$ & $90.3(6.7)^{\mathrm{a}}$ \\
\hline \multicolumn{5}{|l|}{ Hydrology } \\
\hline Stream width (m) & $66(7)^{\mathrm{ab}}$ & $32(6)^{\mathrm{b}}$ & $95(14)^{\mathrm{a}}$ & $111(26)^{\mathrm{a}}$ \\
\hline Water width (m) & $38(6)^{\mathrm{ab}}$ & $16(4)^{\mathrm{b}}$ & $50(20)^{\mathrm{a}}$ & $65(16)^{a}$ \\
\hline Depth (cm) & $81(17)$ & $46(5)$ & $148(46)$ & $118(27)$ \\
\hline Current velocity $\left(\mathrm{m} . \mathrm{s}^{-1}\right)$ & $0.8(0.2)^{\mathrm{a}}$ & $1.1(0.1)^{\mathrm{a}}$ & $0.5(0.3)^{\mathrm{ab}}$ & $0.4(0.1)^{\mathrm{b}}$ \\
\hline \multicolumn{5}{|l|}{ Land cover (\%) } \\
\hline Urban & $4.1(2.1)$ & $4.4(3.4)$ & $3.1(1.1)$ & $2.3(0.6)$ \\
\hline Paddy field & $27.5(5.3)$ & $22.4(5.7)$ & $38.7(6.8)$ & $52.1(6.9)$ \\
\hline Forest & $64.7(7.2)$ & $72(8.6)$ & $54(8.2)$ & $32.8(5.6)$ \\
\hline Grass & $0.8(0.7)$ & $1.1(1.1)$ & $1.4(1)$ & $1.7(0.8)$ \\
\hline Wetland & $1.5(0.8)^{\mathrm{b}}$ & $0.1(0.1)^{b}$ & $1.5(0.4)^{\mathrm{ab}}$ & $5.6(1.4)^{\mathrm{a}}$ \\
\hline Bareland & $1.5(0.8)^{\mathrm{b}}$ & $0.1(0.1)^{\mathrm{b}}$ & $1.5(0.4)^{\mathrm{ab}}$ & $5.6(1.4)^{\mathrm{a}}$ \\
\hline \multicolumn{5}{|l|}{ Biotic indices } \\
\hline Species richness & $11(1)$ & $8(1)$ & $13(2)$ & $11(1)$ \\
\hline Abundance & $79(11)$ & $72(11)$ & $148(46)$ & $74(14)$ \\
\hline Biomass (g) & $501(88)^{\mathrm{b}}$ & $400(53)^{\mathrm{b}}$ & $10199(7743)^{\mathrm{b}}$ & $931(310)^{\mathrm{a}}$ \\
\hline Evenness & $0.69(0.03)$ & $0.69(0.02)$ & $0.74(0.06)$ & $0.78(0.02)$ \\
\hline Shannon diversity & $1.59(0.12)$ & $1.44(0.11)$ & $1.86(0.24)$ & $1.86(0.1)$ \\
\hline Simpson diversity & $0.68(0.04)$ & $0.66(0.03)$ & $0.76(0.06)$ & $0.79(0.02)$ \\
\hline IBI & $81.8(2.2)$ & $79.7(3.9)$ & $85(3.2)$ & $86.5(4.1)$ \\
\hline \multicolumn{5}{|c|}{ Trophic guilds (abundance) (\%) } \\
\hline Omnivores & $94.9(1.6)$ & $84.8(7.3)$ & $83.3(4.6)$ & $93.7(3)$ \\
\hline Herbivores & $0(0)$ & $0(0)$ & $0(0)$ & $0.4(0.4)$ \\
\hline Insectivores & $4.5(1.6)$ & $15.2(7.3)$ & $6.5(4.2)$ & $1(0.5)$ \\
\hline Piscivores & $0.7(0.5)$ & $0(0)$ & $10.2(6)$ & $4.9(2.9)$ \\
\hline \multicolumn{5}{|c|}{ Trophic guilds (biomass) (\%) } \\
\hline Omnivores & $95.5(1.5)$ & $89.9(4.7)$ & $80.3(11.8)$ & $92.1(4.4)$ \\
\hline Herbivores & $0(0)$ & $0(0)$ & $0(0)$ & $0(0)$ \\
\hline Insectivores & $9.4(2.1)$ & $24.1(10.9)$ & $15.2(10.2)$ & $1.2(0.7)$ \\
\hline Piscivores & $2.7(1.8)$ & $0(0)$ & $48.4(20.7)$ & $24(12.5)$ \\
\hline
\end{tabular}

the dam, resulting in population or community fragmentation and isolation (Neraas and Sprull, 2001; Olden et al., 2001). These results are in accordance with many previous studies. For instance, Marchetti and Moyle (2001) reported that native fish species were closely associated with colder temperatures, a faster stream flow, and complex habitats, whereas nonnative fish species were negatively correlated with increased stream flow. Furthermore, Copp (1990) suggested that because of a flow regime conversion from lotic to lentic, generalist fish became dominant, whereas salmonids and pelagic spawning fish were eliminated (e.g., Dauble and Geist, 2000). Additionally, blocking fish migration to upstream of a dam can cause the decline of migratory species upstream, interfering with the completion of their life cycles (Welcomme, 1992; Bunn and Arthington, 2002). Anderson et al. (2006) also indicated that fish communities varied greatly between directly up- and downstream of a dam, suggesting that the dam blocked the migration or movement of fishes. As dams reduce the flow peak from floods, and regulate the flow regime (mainly maintaining stable flow regimes), they change lotic habitats into lentic ones. This aids lentic or newly introduced species to outcompete original species, especially lotic fishes (Moyle and Light, 1996; Agostinho et al., 2004; Poulet, 2007). In addition to flow regimes, dams modify the physical habitat conditions, such as increasing the depth and width, and water siltation (Kruk and Penczak, 2003; McLaughlin et al., 2006).

The indicator species analysis also supports the conclusion that dams can alter fish communities (Table 2). The species that are mainly found in deep water and slow current velocity (Kim et al., 1996; Lee et al., 2009) were grouped in cluster 4, including M. longidorsalis, A. yamatsutae and $C$. splendidus. Largemouth bass (M. salmoides) was selected as an indicator species for cluster 3, which included the upstream study site closest to the dam (M7). This species is exotic in Korea, and it is listed in the " 100 of the World's Worst Invasive Alien Species" (Lowe et al., 2000). Largemouth bass, as an apex 

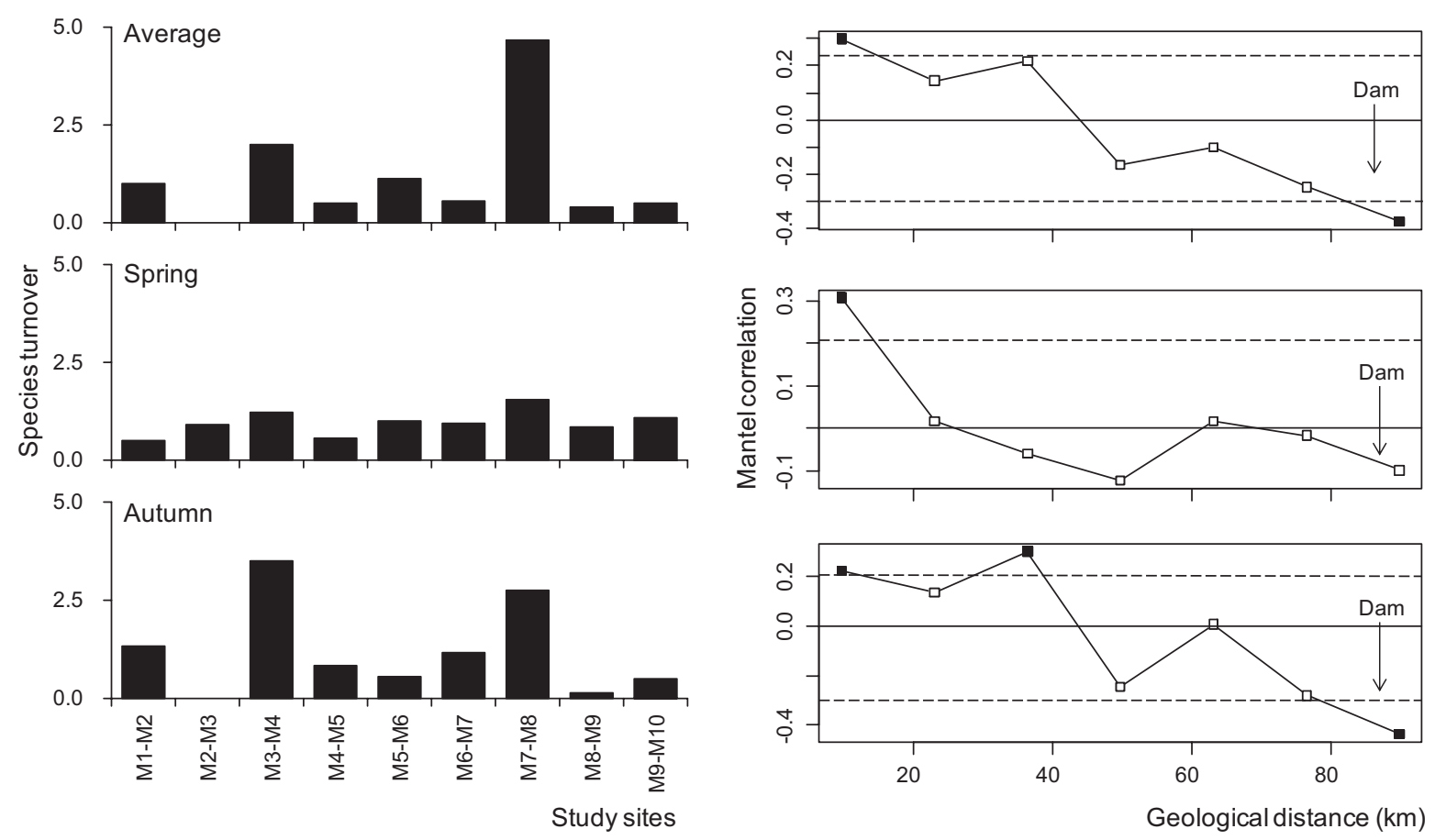

Fig. 4. (a) Species turnover rates between two nearest sites and (b) Mantel correlogram for spatial autocorrelation in fish community. Closed squares indicate statistically significant correlation (assessed using a Bonferroni correction) between site dissimilarity and geographical distance $(P<0.05)$, whereas open ones are not statistically significant. Dotted lines represent the significant level $(P<0.05)$.

Table 3. Indicator species in each cluster based on fish abundance. Species with an IndVal $>25$ were considered indicator species. The significance of the indicator values for each species was tested with a Monte Carlo permutation.

\begin{tabular}{|c|c|c|c|c|}
\hline Species & Trophic guilds & Clusters & IndVal & $P$ \\
\hline Zacco koreanus & Omnivores & 1 & 63 & 0.0003 \\
\hline Liobagrus andersoni & Insectivores & 1 & 38 & 0.0357 \\
\hline Odontobutis interrupta & Omnivores & 2 & 68 & 0.0003 \\
\hline Hemibarbus longirostris & Omnivores & 3 & 58 & 0.0006 \\
\hline Carassius auratus & Omnivores & 3 & 68 & 0.0018 \\
\hline Siniperca scherzeri & Piscivores & 3 & 60 & 0.0021 \\
\hline Pseudogobio esocinus & Omnivores & 3 & 45 & 0.0189 \\
\hline Micropterus salmoides & Piscivores & 3 & 40 & 0.0201 \\
\hline Cyprinus carpio & Omnivores & 3 & 40 & 0.0221 \\
\hline Pseudobagrus fulvidraco & Omnivores & 3 & 35 & 0.0301 \\
\hline Coreoleuciscus splendidus & Omnivores & 4 & 69 & 0.0001 \\
\hline Microphysogobio longidorsalis & Omnivores & 4 & 59 & 0.002 \\
\hline Sarcocheilichthys variegatus wakiyae & Omnivores & 4 & 59 & 0.0039 \\
\hline Acheilognathus yamatsutae & Omnivores & 4 & 49 & 0.0101 \\
\hline Coreoperca herzi & Piscivores & 4 & 47 & 0.0166 \\
\hline
\end{tabular}

predator in freshwater ecosystems (García-Berthou, 2002), can induce changes in fish community structures (Carpenter and Kitchell, 1993; Ahrenstorff et al., 2009), and out-compete native piscivores (e.g., Bacheler et al., 2004; Ko et al., 2008; Lee et al., 2009). Standing water bodies, created through the constructed impoundments, are preferable for introduced species (here, largemouth bass), which are generally abundant in lakes or reservoirs, and river backwaters in their original ranges (Moyle, 1986; Bunn and Arthington, 2002; Gehrke et al., 2002; McLaughlin et al., 2006). After the introduction to Korea of the largemouth bass, which has been designated as an invasive and ecosystem hazard species here since 1998, severe impacts have been reported, including diversity loss, dominance increase, and a decline in species richness (Kim et al., 1996; NFRDI, 2010). According to the NFRDI (2013), several fish have continuously been released in the research area near the dam, in order to increase fishermen's incomes and fishery resources in inland waters. Recently (i.e., 2007-2011), C. auratus $\left(1.38 \times 10^{6}\right.$ individuals), Pseudobagrus fulvidraco $\left(9.5 \times 10^{4}\right.$ individuals), Leiocassis ussuriensis $\left(2.4 \times 10^{4}\right.$ individuals $)$, Plecoglossus 
altivelis $\left(2.2 \times 10^{4} \quad\right.$ individuals $), \quad$ Siniperca scherzeri $\left(1.3 \times 10^{4}\right.$ individuals) and Aucoba japonica $\left(5.0 \times 10^{4}\right.$ individuals) were released as fry near site M7, close to the dam (NFRDI, 2013). However, the successful establishment of the highly predatory largemouth bass could seriously affect these valuable fishery resources. Study site M7 was changed into a representative artificial lentic area, in order to provide agricultural water after dam construction. Due to the cease of water current, sediments have continuously accumulated here, and the relative ratio of small substrates, such as sand, is very abundant. This area also especially harbors various aquatic insects, which the bass prefer in addition to the fish fry. Furthermore, submerged plants in the riparian area provide the fish species' habitats as well as their spawning areas (Hong and Son, 2003). For this reason, bass fry (body length: $5-10 \mathrm{~cm}$ ), as well as bass adult fish (more than $30 \mathrm{~cm}$ ) have been continuously collected from M7 (Na, 2014). Since the abundance of bass can increase with time, continuous monitoring and efficient management policies are necessary to block their further establishment (e.g., artificial spawning grounds, NFRDI, 2010).

In general, although dams contribute various services, including efficient power generation, flood control, water irrigation and recreational purposes, they have had detrimental impacts on aquatic ecosystems (Bebnarek, 2001). More trials are therefore needed for mitigating the severe impacts of dams on the physical and biological factors of aquatic ecosystems. For instance, modifying dam operating regimes, which become more similar to natural thermal and flow regimes, could provide more suitable habitats to native species (Konrad et al., 2011). Kiernan et al. (2012) reported that after mimicking natural flow regimes downstream of a dam, the native species became dominant there. In addition, positive effects regarding recovery of the "original" fish community after dam removal have been widely reported, as the restored unregulated natural flow and thermal regimes would result in original sediment composition, and henceforth enhance the preferred spawning habitats (Bebnarek, 2001). It would be essential to continuously monitor the aquatic ecosystem, especially near the dam (both up- and downstream), to protect and conserve aquatic resources.

Acknowledgements. This work was supported by a grant from the National Fisheries Research and Development Institute (grant no. R2016035).

\section{References}

Agostinho A.A., Gomes L.C., Verissimo S. and Okada E.K., 2004. Flood regime, dam regulation and fish in the Upper Parana River: effects on assemblage attributes, reproduction and recruitment. Rev. Fish Biol. Fish., 14, 11-19.

Ahrenstorff T.D., Sass G.G. and Helmus M.R., 2009. The influence of littoral zone coarse woody habitat on home range size, spatial distribution, and feeding ecology of largemouth bass (Micropterus salmoides). Hydrobiologia, $623,223-233$.

Albert J.S. and Reis R.E., 2011. Historical Biogeography of Neotropical Freshwater Fishes, University of California Press, Berkeley, California, 308 p.

Alhoniemi E., Himberg J., Parhankangas J. and Vesanto J., 2000. SOM Toolbox. Available online at: http:// www.cis.hut.fi/projects/somtoolbox.

Anderson E.P., Freeman M.C. and Pringle C.M., 2006. Ecological consequences of hydropower development in Central America: impacts of small dams and water diversion on neotropical stream fish assemblages. River Res. Appl., 22, 397-411.

Araújo F.G., Pinto B.C.T. and Teixeira T.P., 2009. Longitudinal patterns of fish assemblages in a large tropical river in southeastern Brazil: evaluating environmental influences and some concepts in river ecology. Hydrobiologia, 618, 89-107. doi: http://dx.doi.org/10.1007/s10750-008-9551-5.

Bacheler N.M., Neal J.W. and Noble R.L., 2004. Diet overlap between native bigmouth sleepers (Gobiomorus dormitor) and introduced predatory fishes in a Puerto Rico reservoir. Ecol. Freshw. Fish., 13, 111-118.

Bae M.J., Li F., Kwon Y.S., Chung N., Choi H., Hwang S.J. and Park Y.S., 2014. Concordance of diatom, macroinvertebrate and fish assemblages in streams at nested spatial scales: implications for ecological integrity. Ecol. Indic., 47, 89-101.

Bae M.J., Merciai R., Benejam L., Sabater S. and GarcíaBerthou E., 2015. Small weirs, big effects: disruption of water temperature regimes with hydrological alteration in a mediterranean stream. River Res. Appl. (In press, available: 10.1002/rra.2871).

Bain M.B., Finn J.T. and Booke H.E., 1988. Streamflow regulation and fish community structure. Ecology, 69, 382-392.

Bebnarek A.T., 2001. Undamming rivers: a review of the ecological impacts of dam removal. Environ. Manage., 27, 803-814.

Bonada N., Rieradevall M. and Prat N., 2007. Macroinvertebrate community structure and biological traits related to flow permanence in a Mediterranean river network. Hydrobiologia, 589, 91-106.

Bunn S.E., and Arthington A.H., 2002. Basic principles and ecological consequences of altered flow regimes for aquatic biodiversity. Environ. Manage., 30, 492-507.

Carpenter S.R. and Kitchell J.F. (eds), 1993. The Trophic Cascade in Lakes, Cambridge University Press, New York.

Céréghino R. and Park Y.S., 2009. Review of the self-organizing map (SOM) approach in water resources: commentary. Environ. Modell. Softw., 24, 945-947.

Chaves M.L., Rieradevall M., Chainho P., Costa M.J. and Prat N., 2008. Macroinvertebrate communities of non-glacial high altitude intermittent streams. Freshw. Biol., 53, 55-76.

Copp G.H., 1990. Effect of regulation on $0+$ fish recruitment in the Great Ouse, a lowland river. Regul. Rivers Res. Manage., 5, 251-263.

Cushman R.M., 1985. Review of ecological effects of rapidly varying flows downstream from hydroelectric facilities. Fish. Manage., 5, 330-339.

Dauble D.D. and Geist D.R., 2000. Comparison of mainstem spawning habitats for two populations of fall Chinook salmon in the Columbia River Basin. Regul. Rivers Res. Manage., 16, 345-361. 
Dufrêne M. and Legendre P., 1997. Species assemblages and indicator species: the need for a flexible asymmetrical approach. Ecol. Monogr., 67, 345-366.

Falke J.A. and Gido K.B., 2006. Spatial effects of reservoirs on fish assemblages in Great Plains streams in Kansas, USA. River Res. Appl., 22, 55-68.

García-Berthou E., 2002. Ontogenetic diet shifts and interrupted piscivory in introduced largemouth bass (Micropterus salmoides). Int. Rev. Hydrobiol., 87, 353-363.

Gasith A. and Resh V.H., 1999. Streams in Mediterranean climate regions: abiotic influences and biotic responses to predictable seasonal events. Annu. Rev. Ecol. Syst., 30, 51-81.

Gehrke P.C., Gilligan D.M. and Barwick M., 2002. Changes in fish communities of the Shoalhaven River 20 years after construction of Tallowa Dam, Australia. River Res. Appl., 18, 265-286.

Helms B.S., Werneke D.C., Gangloff M.M., Hartfield E.E. and Feminella J.W., 2011. The influence of low-head dams on fish assemblages in streams across Alabama. J. North Am. Benthol. Soc., 30, 1095-1106.

Hong Y.P. and Son Y.M., 2003. Studies on the interspecific association of community including Micropterus salmoides population, introduced fish in Korea. Korean J. Ichthyol., 15, 61-68.

Johnson P.T.J., Olden J.D. and Zanden M.J.V., 2008. Dam invaders: impoundments facilitate biological invasions into freshwaters. Front. Ecol. Environ., 6, 357-363.

Kiernan J.D., Moyle P.B. and Crain P.K., 2012. Restoring native fish assemblages to a regulated California stream using the natural flow regime concept. Ecol. Appl., 22, 1472-1482.

Kim D.H., Hwang S.O., Yang H.J., Jeon S.R., Choi S.S., Kim I.S. and Choi C.G., 1996. Studies on the Distribution and Effect of the Exotic Fishes in Dam Reservoir, Korean Water Resources Corporation, Daejeon, Korea, 258 p.

Kim I.S. and Park J.Y., 2002. Freshwater Fish of Korea, Kyohak Publishing, Seoul, 467 p.

Kinsolving A.D. and Bain M.B., 1993. Fish assemblage recovery along a riverine disturbance gradient. Ecol. Appl., 3, 531-544.

Ko M.H., Park J.Y. and Lee Y.J., 2008. Feeding habits of an introduced large mouth bass, Micropterus salmoides (Perciformes; Centrarchidae), and its influence on ichthyofauna in the Lake Okjeong, Korea. Korean J. Ichthyol., 20, 36-44.

Kohonen T., 2001. Self-Organizing Maps (3rd edn), Springer, Berlin.

Konrad C.P., Olden J.D., Lytle D.A., Melis T.S., Schmidt J.C., Bray E.N., Freeman M.C., Gido K.B., Hemphill N.P., Kennard M.J., McMullen L.E., Mims M.C., Pyron M., Robinson C.T. and Williams J.G., 2011. Large-scale flow experiments for managing river systems. BioScience, 61, 948-959.

Kruk A. and Penczak T., 2003. Impoundment impact on populations of facultative riverine fish. Int. J. Limnol., 39, 197-210.

Lee W.O., Yang H., Yoon S.W. and Park J.Y., 2009. Study on the feeding habits of Micropterus salmoides in Lake Okjeong and Lake Yongdam, Korea. Korean J. Ichthyol., 21, 200-207.

Legendre P. and Legendre L., 1998. Numerical Ecology, Elsevier, Amsterdam.

Lowe S., Browne M., Boudjelas S. and De Poorter M., 2000. 100 of the world's worst invasive alien species. A selection from the global invasive species database. ISSG, SSC and IUCN. Available online at: http://www.issg.org/ booklet.pdf.

Magilligan F.J. and Nislow K.H., 2005. Changes in hydrologic regime by dams. Geomorphology, 71, 61-78.

Mantel N., 1967. The detection of disease clustering and a generalized regression approach. Cancer Res., 27, 209-220.

March J.G., Benstead J.P., Pringle C.M. and Scatena F.N., 2003. Damming tropical island streams: problems, solutions, and alternatives. BioScience, 53, 1069-1078.

Marchetti M.P. and Moyle P.B., 2001. Effects of flow regime on fish assemblages in a regulated California stream. Ecol. Appl., 11, 530-539.

Matthews W.J., 1998. Patterns in Freshwater Fish Ecology, Chapman and Hall, New York.

McCune B. and Mefford M.J., 2006. PC-ORD. Multivariate Analysis of Ecological Data. Version 5. MjM Software, Gleneden Beach, Oregon, USA. MjM Software, Gleneden Beach, Oregon.

McLaughlin R.L., Porto L., Noakes D.L.G., Baylis J.R., Carl L.M., Dodd H.R., Goldstein J.D., Hayes D.B. and Randall R.G., 2006. Effects of low-head barriers on stream fishes: taxonomic affiliations and morphological correlates of sensitive species. Can. J. Fish. Aquat. Sci., 63, 766-779.

Mims M.C. and Olden J.D., 2012. Life history theory predicts fish assemblage response to hydrologic regimes. Ecology, 93, 35-45.

Mims M.C. and Olden J.D., 2013. Fish assemblages respond to altered flow regimes via ecological filtering of life history strategies. Freshw. Biol., 58, 50-62.

MOE/NEIR (Ministry of Environment/National Institute of Environmental Research), 2008. The Survey and Evaluation of Aquatic Ecosystem Health in Korea, MOE/NIER, Inchon, Korea (in Korean with English summary).

Moyle P.B., 1986. Fish introductions into North America: patterns and ecological impact. In: Ecology of biological invasions of North America and Hawaii, Springer, New York, pp. 27-43.

Moyle P.B., 2002. Inland Fishes of California, University of California Press, Berkeley, California, USA.

Moyle P.B. and Light T., 1996. Biological invasions of fresh water: empirical rules and assembly theory. Biol. Conserv., 78, 149-161.

Moyle P.B. and Marchetti M.P., 2006. Predicting invasion success: freshwater fishes in California as a model. BioScience, 56, 515-524.

Na J.H., 2014. Inland fisheries stock management and estimation of potential yield in Geo-san Lake. Doctor Thesis, Pukyong National University, Korea.

Neraas L.P. and Spruell P., 2001. Fragmentation of riverine systems: the genetic effects of dams on bull trout (Salvelinus confluentus) in the Clark Fork River system. Mol. Ecol., 10, 1153-1164.

NFRDI, 2010. Distribution, utilization and management strategy of introduced freshwater fish. Report of National Fisheries Research and Development Institute, Busan, 121 p.

NFRDI, 2013. Development of inland fisheries using ecosystem management approach and biodiversity increasing research. Report of National Fisheries Research and Development Institute, Busan, 76 p. 
Oden N.L. and Sokal R.R., 1986. Directional autocorrelation: an extension of spatial correlograms to two dimensions. Syst. Zool., 35, 608-617.

Oksanen J., Kindt R., Legendre P. and O'Hara B., 2007. Vegan: community ecology package. $\mathrm{R}$ package version 1.8-5, Accessed online 10 April 2007, http://cran.r-project. org/

Olden J.D., Jackson D.A. and Peres-Neto P.R., 2001. Spatial isolation and fish communities in drainage lakes. Oecologia, $127,572-585$.

Ostrand K.G. and Wilde G.R., 2002. Seasonal and spatial variation in a prairie stream-fish assemblage. Ecol. Freshw. Fish, 11, 137-149.

Peterson W.T. and Keister J.E., 2003. Interannual variability in copepod community composition at a coastal station in the northern California Current: a multivariate approach. Deep Sea Res., 50, 2499-2517.

Poff N.L. and Hart D.D., 2002. How dams vary and why it matters for the emerging science of dam removal. BioScience, 52, 659-668.

Poff N.L., Olden J.D., Merritt D.M. and Pepin D.M., 2007. Homogenization of regional river dynamics by dams and global biodiversity implications. Proc. Natl. Acad. Sci. USA, 104, 5732-5737.

Poulet N., 2007. Impact of weirs on fish communities in a piedmont stream. River Res. Appl., 23, 1038-1047.

Power M.E., Parker M.S. and Dietrich W.E., 2008. Seasonal reassembly of a river food web: floods, droughts, and impacts of fish. Ecol. Monogr., 78, 263-282.
Schmidt J.C., Webb R.H., Valdez R.A., Marzolf G.R. and Stevens L.F., 1998. Science and values in river restoration in the grand canyon. BioScience, 48, 735-747.

Sokal R.R. and Rohlf F.J., 1995. Biometry: the Principles and Practice of Statistics in Biological Research (3rd edn), W.H. Freeman and Co., New York.

StatSoft, Inc., 2005. STATISTICA (data analysis software system), version 8, http://www.statsoft.com.

The Mathworks, 2001. MATLAB, Version 6.1; Software for Technical Computation, The Mathworks Inc., Natick, MA, USA.

Travnicheck V.H., Bain M.B. and Maceina M.J., 1995. Recovery of a warm water fish assemblage after the initiation of minimum-flow release downstream from a hydroelectric dam. Trans. Am. Fish. Soc., 124, 836-844.

Vesanto J., 2000. Neural network tool for data mining: SOM Toolbox. In: Proceedings of Symposium on Tool Environments and Development Methods for Intelligent Systems (TOOLMET2000). Oulun yliopistopaino, Oulu, Finland, 184-196.

Vila-Gispert A., García-Berthou E. and Moreno-Amich R., 2002. Fish zonation in a Mediterranean stream: effects of human disturbances. Aquat. Sci., 64, 163-170.

Welcomme R.L. 1992., River conservation - future prospects. In: Boon P.J., Calow P. and Petts G.E. (eds.), River Conservation and Management, John Wiley \& Sons, Chichester, UK, 454-462.

Yarnell S.M., Viers J.H. and Mount J.F., 2010. Ecology and management of the spring snowmelt recession. BioScience, $60,114-127$. 


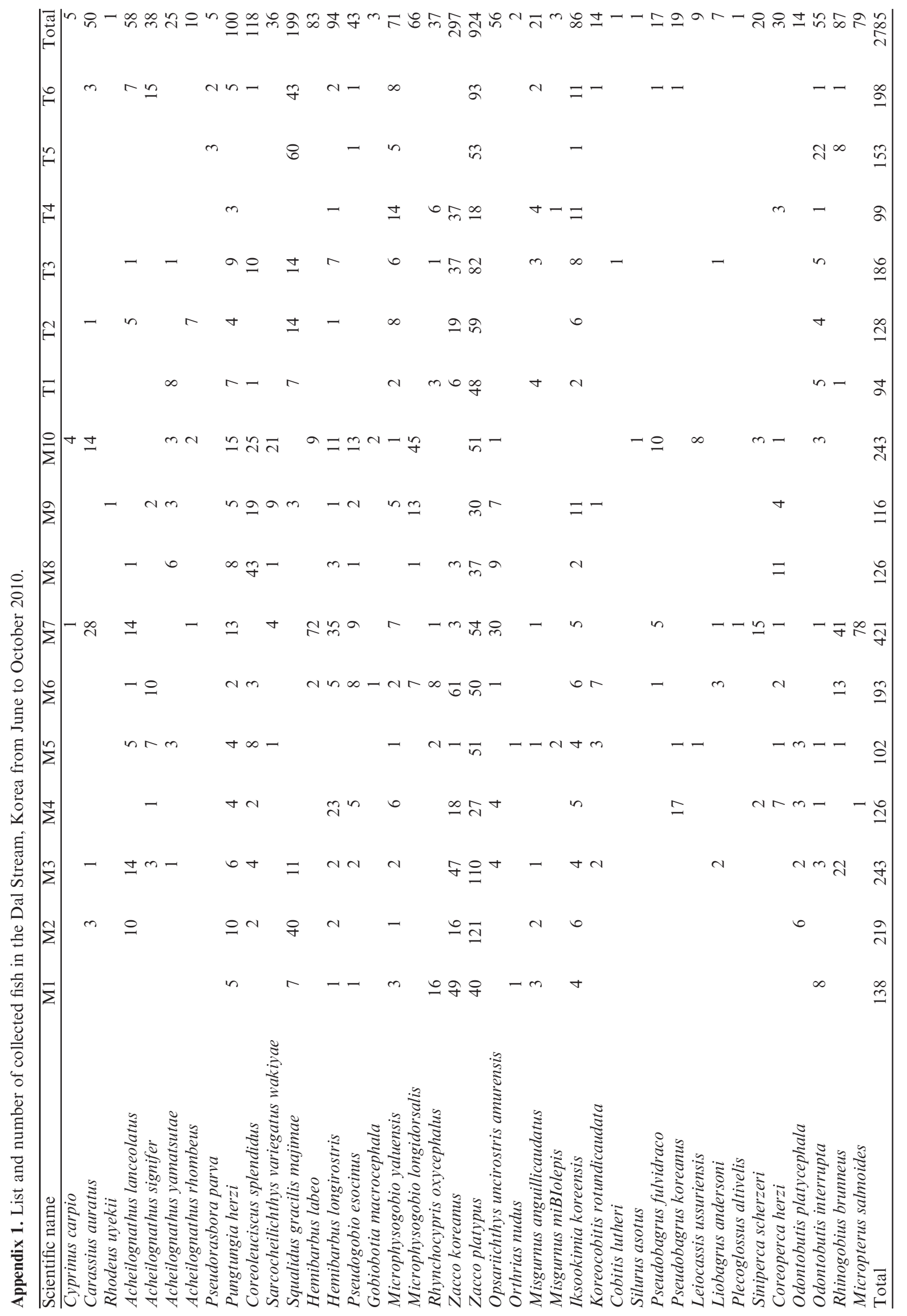

